\title{
ISB News July 2010
}

\section{From the ICB2011 Chair (and President-Elect)}

The International Society of Biometeorology, formed in 1956 , is pleased to announce that its 19th International Congress of Biometeorology (ICB2011) will be held 5-9 December 2011 at The University of Auckland, Auckland, New Zealand. The Congress theme will be Climate and Society.

The overall aim of ICB2011 is to explore the links between climate and society. This is because a central ethos of the interdisciplinary science of Biometeorology is the desire to understand interactions between atmospheric processes and living organisms - plants, animals and humans. Such interactions are fundamental to the well-being and sustainability of society at a range of geographical and time scales. Given this we anticipate the participation of scientists including social scientists and health scientists from a wide range of fields in ICB2011.
At this stage of the planning process the general ICB2011 programme structure will include plenary sessions, parallel paper sessions, fieldtrips (optional), and social events such as an ice breaker and congress dinner.

For further information regarding the ICB2011 venue, location, and Secretariat contact details, as well as to register your interest, please visit the ICB2011 web site: http://www.icb2011.com/

Information regarding submission of abstracts, registration, accommodation, fieldtrips, social events, and other features of the Congress will be added to the ICB2011 web site over the coming months. We look forward to welcoming you to New Zealand.

Glenn R. McGregor

ISB President-Elect

School of Environment

The University of Auckland

g.mcgregor@auckland.ac.nz 